\begin{tabular}{|c|c|}
\hline Title: & $\begin{array}{l}\text { A Transformerless Single-Phase PV Inverter Circuit for Thin-Film or Back-Side } \\
\text { Contacted Solar Modules }\end{array}$ \\
\hline Authors: & Mario Gommeringer, Felix Kammerer, Alexander Schmitt, Michael Braun \\
\hline Institute: & $\begin{array}{l}\text { Karlsruhe Institute of Technology (KIT) } \\
\text { Elektrotechnisches Institut (ETI) }\end{array}$ \\
\hline Type: & Conference Proceedings \\
\hline Published at: & $\begin{array}{ll}\text { Industrial Electronics Society, IECON } 2014 \text { - 40th Annual Conference of the IEEE } \\
\text { Date of Conference: } & \text { Oct. } 292014 \text { - Nov. } 12014 \\
\text { Page(s): } & 1148-1153 \\
\text { Conference Location: } & \text { Dallas, TX, USA } \\
\text { Publisher: } & \text { IEEE } \\
\text { ISBN: } & 978-1-4799-4033-2 \\
& 978-1-4799-4032-5\end{array}$ \\
\hline Hyperlinks: & 10.1109/IECON.2014.7048647 \\
\hline
\end{tabular}

(c) 2014 IEEE. Personal use of this material is permitted. Permission from IEEE must be obtained for all other uses, in any current or future media, including reprinting/republishing this material for advertising or promotional purposes, creating new collective works, for resale or redistribution to servers or lists, or reuse of any copyrighted component of this work in other works. 


\title{
A Transformerless Single-Phase PV Inverter Circuit for Thin-Film or Back-Side Contacted Solar Modules
}

\author{
Mario Gommeringer, Felix Kammerer, Alexander Schmitt, Michael Braun \\ Institute of Electrical Engineering (ETI) - Electrical Drives and Power Electronics \\ Karlsruhe Institute of Technology (KIT) \\ 76131 Karlsruhe, Germany \\ Email: mario.gommeringer@kit.edu
}

\begin{abstract}
This paper deals with a new transformerless single-phase photovoltaic inverter circuit. The circuit is well suited for thin-film or back-side contacted solar modules because one pole of the solar module can be directly connected to the neutral conductor. The circuit uses a flying capacitor for one of both half-waves, requires only five transistors and is capable of providing inductive as well as capacitive reactive power.
\end{abstract}

\section{Keywords - Power Electronic Converters}

\section{INTRODUCTION}

Solar inverters have to fulfill several requirements dependent on the configuration of the photovoltaic system. Many thin-film solar modules require positive voltages to earth to prevent them from an irreversible damage by corrosion of the Transparent Conductive Oxide (TCO). In contrast to this, many back-side contacted solar modules require negative voltages to earth to achieve a high efficiency. The technical background of these effects is described in [1] and [2]. Furthermore, some grid codes, e.g. [3], specify that photovoltaic inverters must be able to provide reactive power at the AC-side.

Efficient and transformerless single phase solar inverters are described in [4-8]. They are well-suited for standard silicon modules but it is not possible to connect one pole of the solar generator to earth. Furthermore capacitive leakage currents with fundamental grid frequency occur at the solar modules because the DC input is floating. Inverters with transformer [9] allow a galvanic isolation between input and output but they are usually less efficient and more bulky than transformerless circuits. A transformerless circuit with flying inductor, where one pole of the solar modules can be directly connected to the neutral conductor is described in [10]. However, this topology is not capable of delivering reactive power at the AC-side. A combination of a boost converter with a DC-AC inverter for the usage with thin-film solar modules is described in [11]. The additional boost converter requires additional components and causes additional losses. The circuit described in [12] allows a connection of one pole of the solar modules with earth and is capable of delivering reactive power at the AC-side. There, a flying inductor is used to transfer energy from the solar module to an internal DC-Link. Inductors have a long lifespan compared to electrolytic capacitors, but it is disadvantageous that they require much more space per storable electrical energy than flying electrolytic or flying film capacitors. The circuit described in [13] uses a flying capacitor which is charged from the DC-side during the free-wheeling states. This inverter allows a connection of one pole of the solar modules with earth but the flying capacitor has to be used for both halfwaves. Another circuit where one pole of the solar module string is connected to the neutral conductor is described in [14]. That circuit requires only five transistors and is capable of delivering inductive as well as capacitive reactive power but is built up with a relatively large flying electrolytic capacitor.

In this paper, a new circuit arrangement for the usage with thin-film or back-side contacted solar modules is described and investigated. It uses a relatively small flying film capacitor for the energy transfer during one of both half-waves.

\section{INVERTER CIRCUIT AND FUNCTION}

The circuit diagram of the inverter is shown in Fig. 1. The negative pole of the solar module string G1 is directly connected to the neutral conductor $\mathrm{N}$, which is usually connected to protective earth (PE). This configuration allows the connection of thin-film solar modules. For back-side contacted solar modules, all power semiconductors and electrolytic capacitors have to be connected in reversed polarity, so that the positive pole of the solar module string is connected to the neutral conductor $\mathrm{N}$.

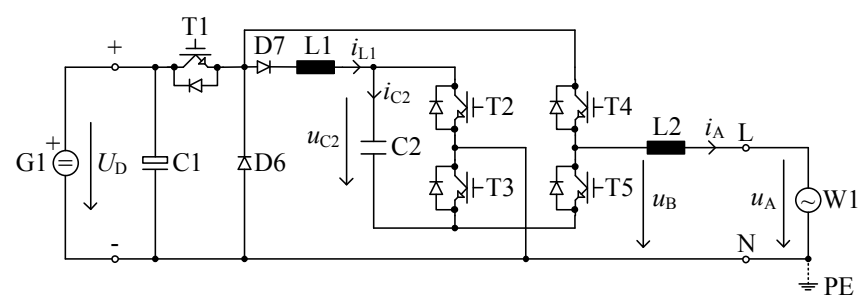

Fig. 1. The single-phase PV inverter circuit

The blocking voltages of all power semiconductors (T1 T5, D6 - D7) do not significantly exceed the voltage $U_{\mathrm{D}}$ of the string, so that standard $1200 \mathrm{~V}$ semiconductors can be used in applications with string voltages up to $800 . .1000 \mathrm{~V}$.

\section{A. Basic switching states}

Fig. 2 shows the switching states 1,2, 3a and $3 \mathrm{~b}$ of the circuit. In $3 a$ and $3 b$ the same switches are closed but in $3 b$ an additional current, flowing through the inductor L1, is highlighted. 


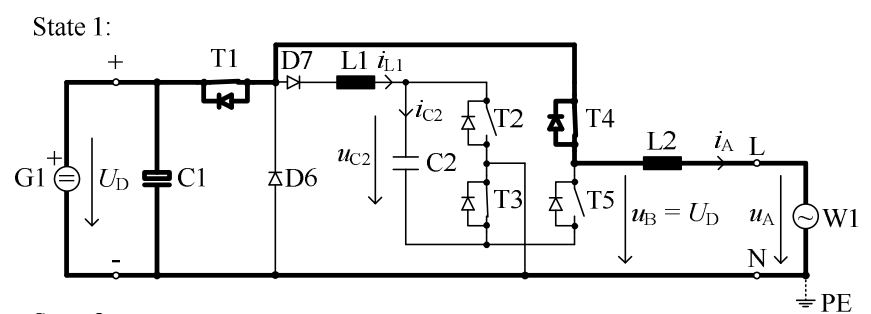

State 3a:

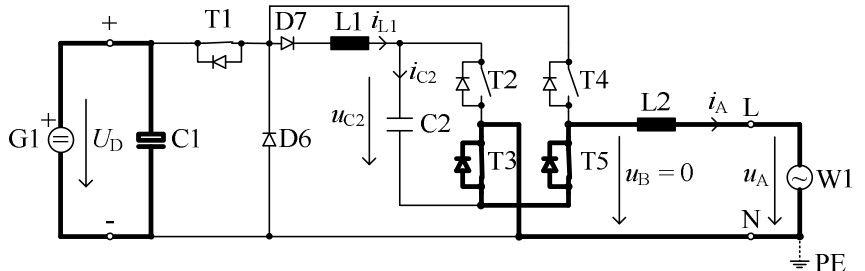

State 2:

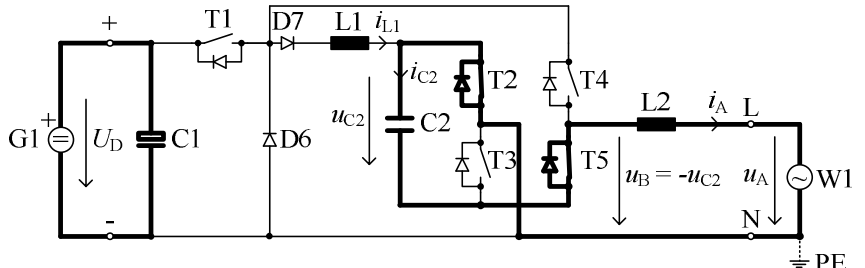

State $3 b$ :

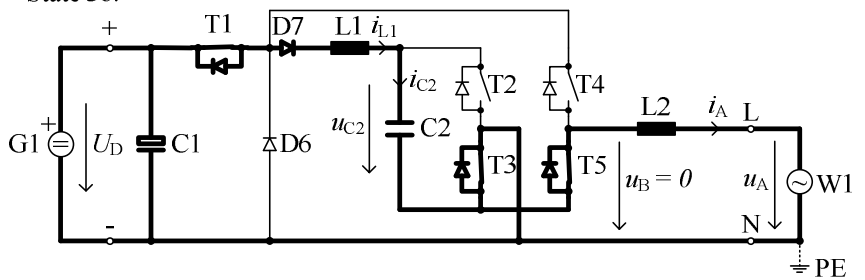

$$
\begin{gathered}
\frac{T_{2}}{T}=\frac{-u_{\mathrm{B}}^{*}}{u_{\mathrm{C} 2}} \\
\frac{T_{3 \mathrm{~b}}}{T}=1-\frac{-u_{\mathrm{B}}^{*}}{u_{\mathrm{C} 2}}
\end{gathered}
$$

The circuit is capable of providing reactive power at the $\mathrm{AC}$-side because energy from the $\mathrm{AC}$ side can be stored in its capacitors. If $u_{\mathrm{b}}^{*}$ is positive and $i_{\mathrm{A}}$ is negative, energy is transferred from $\mathrm{W} 1$ to $\mathrm{C} 1$. If $u_{\mathrm{b}}{ }_{\mathrm{b}}$ is negative and $i_{\mathrm{A}}$ is positive, energy is transferred from $\mathrm{W} 1$ to $\mathrm{C} 2$.

The described circuit and its function is close to [14] but in contrast to [14] the flying capacitor $\mathrm{C} 2$ is charged by a DLC (diode, inductor, capacitor) circuit. This allows the use of a very small capacitance value for C2. A DLC circuit for charging a flying capacitor is known from [13]. In [13] the flying capacitor is used to transfer the energy for both halfwaves of the sinusoidal output voltage, whereas the described circuit only uses the flying capacitor for one half-wave. This leads to low losses and a smaller RMS current in the capacitor which is connected parallel to the solar module string (here: C1).

\section{B. Charging process of the flying capacitor}

The energy $\Delta W_{\mathrm{C} 2}$ that is transferred from $\mathrm{C} 2$ to $\mathrm{W} 1$ in state 2 is:

$$
\Delta W_{\mathrm{C} 2}=u_{\mathrm{B}}^{*} \cdot i_{\mathrm{A}} \cdot T
$$

During state 2, the capacitor $\mathrm{C} 2$ is discharged from the voltage $U_{\mathrm{C} 2 \text {, max }}$ to $U_{\mathrm{C} 2 \text {,max }}-\Delta U_{\mathrm{C} 2}$. The voltage difference $\Delta U_{\mathrm{C} 2}$ can be calculated to:

$$
\Delta U_{\mathrm{C} 2}=U_{\mathrm{C} 2, \max }-\sqrt{U_{\mathrm{C} 2, \max }^{2}-\frac{2 \cdot \Delta W_{\mathrm{C} 2}}{C_{2}}}
$$

As long as the reference value $u_{\mathrm{B}}^{*}$ of the output voltage is positive, the states 1 and $3 \mathrm{a}$ are used. In state $1, u_{\mathrm{B}}=U_{\mathrm{D}}$ is applied and in state $3 \mathrm{a}, u_{\mathrm{B}}=0$ is applied by a pulse width modulation. This operation mode is similar to a buck converter. The durations of the states 1 and 3 a during one pulse period $T$ are calculated to:

$$
\begin{gathered}
\frac{T_{1}}{T}=\frac{u_{\mathrm{B}}^{*}}{U_{\mathrm{D}}} \\
\frac{T_{3 \mathrm{a}}}{T}=1-\frac{u_{\mathrm{B}}^{*}}{U_{\mathrm{D}}}
\end{gathered}
$$

$T$ is the reciprocal of the switching frequency $f_{\text {sw }}$ :

$$
T=\frac{1}{f_{\mathrm{sw}}}
$$

As long as $u_{\mathrm{B}}^{*}$ is negative, the states 2 and $3 \mathrm{~b}$ are used. In state $2, u_{\mathrm{B}}=-u_{\mathrm{C} 2}$ is applied and energy is transferred from the flying capacitor $\mathrm{C} 2$ to the AC-grid $\mathrm{W} 1$. In state $3 \mathrm{~b}, u_{\mathrm{B}}=0$ is applied and the capacitor $\mathrm{C} 2$ is recharged from $\mathrm{G} 1$ and $\mathrm{C} 1$ via T1, D7, L1 and T3. The durations of the states 2 and $3 \mathrm{~b}$ are:
The charging process of $\mathrm{C} 2$ is initiated by closing $\mathrm{T} 1$, see Fig. 3. When $\mathrm{T} 1$ is conducting, the half-sinusoidal charging current $i_{\mathrm{L} 1}=i_{\mathrm{C} 2}$ is rising until $u_{\mathrm{C} 2} \approx U_{\mathrm{D}}-U_{\mathrm{f}}$ and then decreasing again. $U_{\mathrm{f}}$ is the sum of the forward voltage drops of $\mathrm{T} 1, \mathrm{D} 7$ and the parallel diode of T3. The charging process is automatically terminated by $\mathrm{D} 7$ when $i_{\mathrm{L} 1}$ reaches zero. Hence, a measurement of $i_{\mathrm{L} 1}$ is not necessary for the operation of the circuit. The blocking voltage of D7 is only a fraction of $U_{\mathrm{D}}$. Therefore, D7 can be a lower voltage type than the other semiconductors.

Assuming, that $C_{1}>>C_{2}$, the charging time $T_{\text {charge,ZCS }}$ which is necessary for a zero-current-switching charging process can be calculated by:

$$
T_{\text {charge }, \mathrm{ZCS}}=\frac{1}{2 \cdot f_{\mathrm{res}}}=\pi \cdot \sqrt{L_{1} \cdot C_{2}}
$$

The energy $W_{\mathrm{L} 1}$, that has to be stored in $\mathrm{L} 1$ is:

$$
W_{\mathrm{L} 1}=\frac{1}{2} \cdot L_{1} \cdot \hat{I}_{\mathrm{L} 1}^{2}=\frac{1}{8} \cdot C_{2} \cdot \Delta U_{\mathrm{C} 2}^{2}
$$

$W_{\mathrm{L} 1}$ is only a fraction of the transferred energy $\Delta W_{\mathrm{C} 2}$ and decreases with increasing DC-voltage $U_{\mathrm{D}}$. Therefore, L1 will 

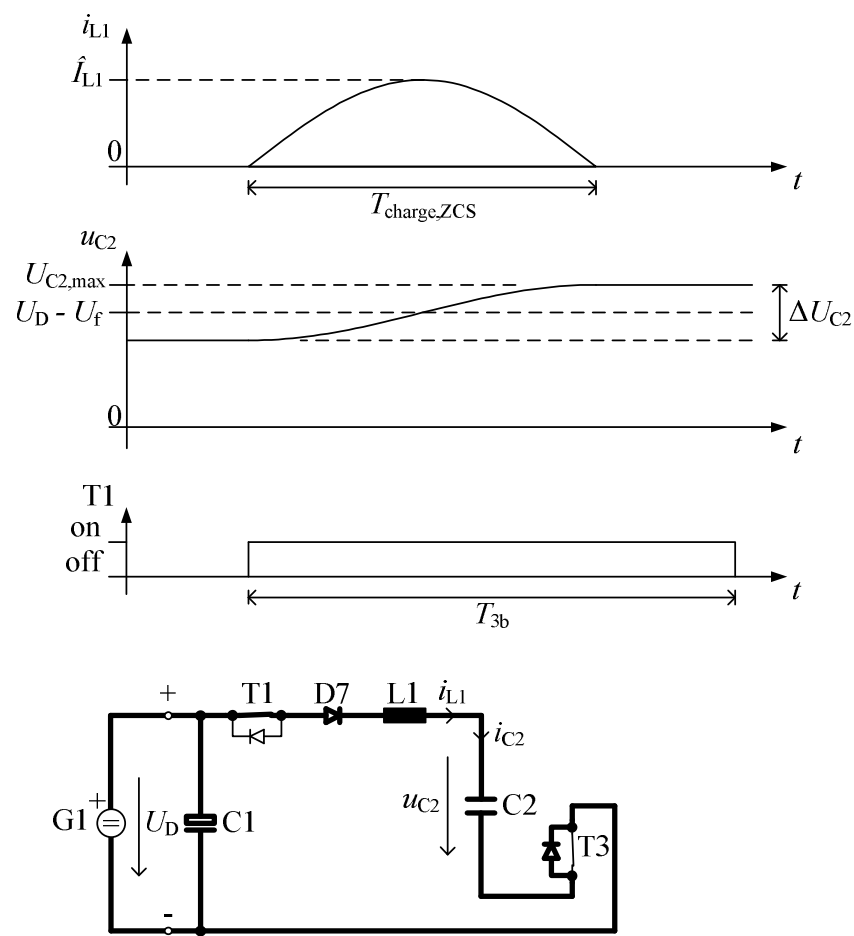

Fig. 3. DLC circuit and charging process of the capacitor $\mathrm{C} 2$

be small and cheap, compared to inductors of boost converters [11] and compared to the flying inductors of the circuits that are described in [10] and [12]. The peak value of the charging current $\hat{I}_{\mathrm{L} 1}=\hat{I}_{\mathrm{C} 2}$ is:

$$
\hat{I}_{\mathrm{L} 1}=\frac{1}{2} \cdot \sqrt{\frac{C_{2}}{L_{1}}} \cdot \Delta U_{\mathrm{C} 2}
$$

The components $\mathrm{D} 7$ and $\mathrm{L} 1$ allow high values of $\Delta U_{\mathrm{C} 2}$ at acceptable values of $\hat{I}_{\mathrm{L} 1}$. Because of this the required capacitance of $\mathrm{C} 2$ is relatively small, so a film capacitor can be used here.

If $\mathrm{T} 1$ is opened before the resonant charging process is completed $\left(T_{3 \mathrm{~b}}<T_{\text {charge,ZCS }}\right)$, the diode D6 protects T1 from overvoltage. The minimum DC-voltage $U_{\mathrm{D}}$ that is necessary for a zero-current switching charging process can be calculated by:

$$
U_{\mathrm{D}, \min , \mathrm{ZCS}}=\sqrt{2} \cdot U_{\mathrm{A}, \mathrm{RMS}} \cdot \frac{T}{T-T_{\text {charge }, \mathrm{ZCS}}}
$$

An operation below $U_{\text {Dmin,ZCS }}$ is possible but additional switching losses occur, when T1 is opened and $i_{\mathrm{L} 1}=i_{\mathrm{C} 2} \neq 0$.

\section{Recommended sequence of switching states}

A recommended sequence of switching states is shown in Fig. 4. When switching from state 1 to 3 and back, a dead time shall be maintained. During the dead time, the transistors T4 and T5 are opened (state 4). When switching from state 2 to 3 and back, a dead time shall be maintained as well. During this dead time, T2 and T3 are opened (state 6). T3 shouldn't be opened as long as T1 is conducting to avoid an overvoltage at T4. For this reason, the states 5 and 7 are added.

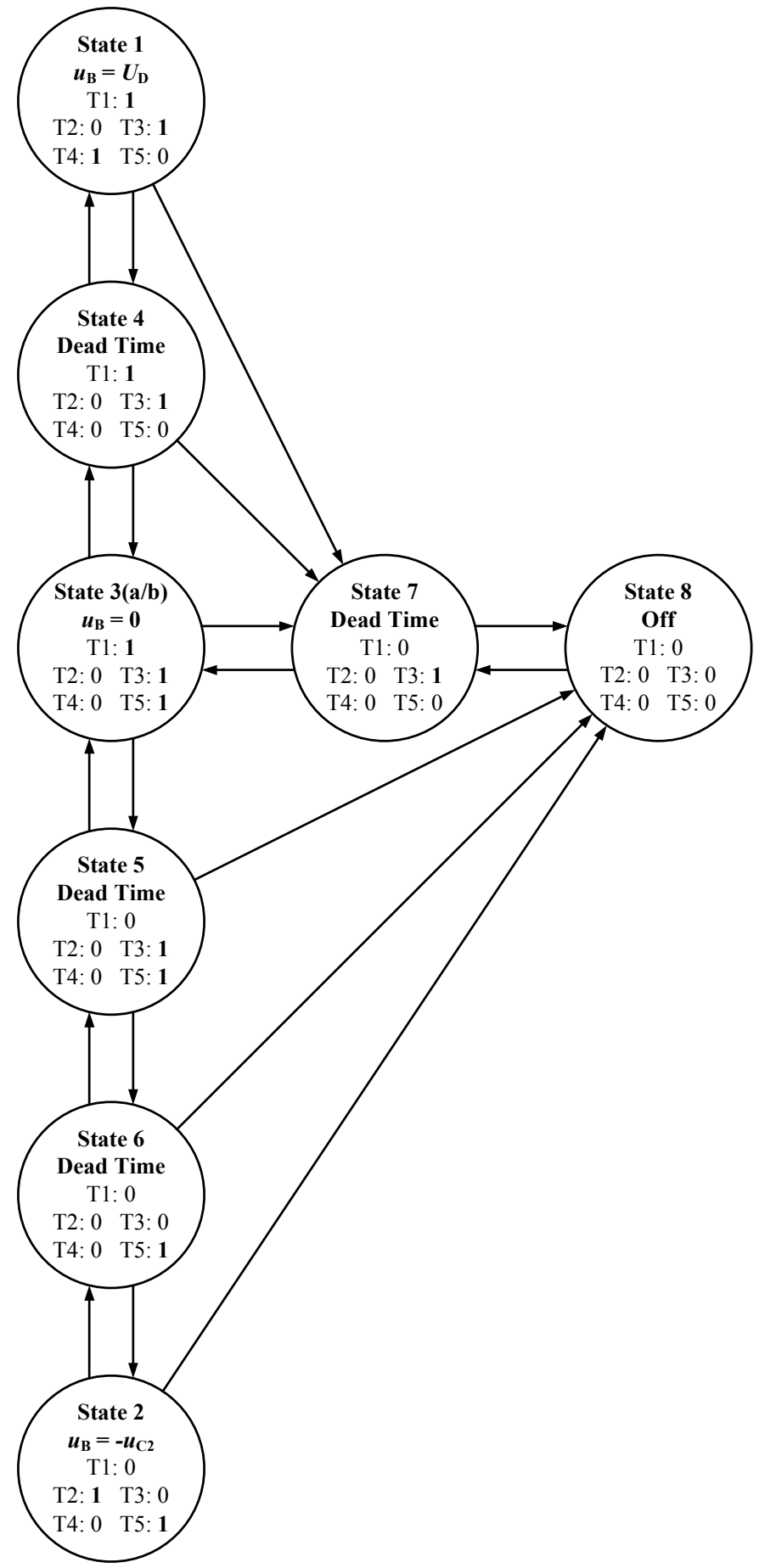

Fig. 4. Recommended sequence of switching states

\section{CONSTRUCTION OF A PROTOTYPE}

A prototype has been built up to validate the function of the circuit (Fig. 5). The technical data of the prototype is listed in TABLE I. Important values and part names of components are listed in TABLE II. The semiconductors T1, D7 and the parallel diode of $\mathrm{T} 3$ have to be dimensioned for the peak charging current $\hat{I}_{\mathrm{L} 1}$. Therefore T1 is realized by two IGBTs in parallel and T3 is an IGBT with external parallel diode. The diode D7 is a type with a blocking voltage of only $200 \mathrm{~V}$ and a 
low forward voltage. All other semiconductors are $1200 \mathrm{~V}$ types.

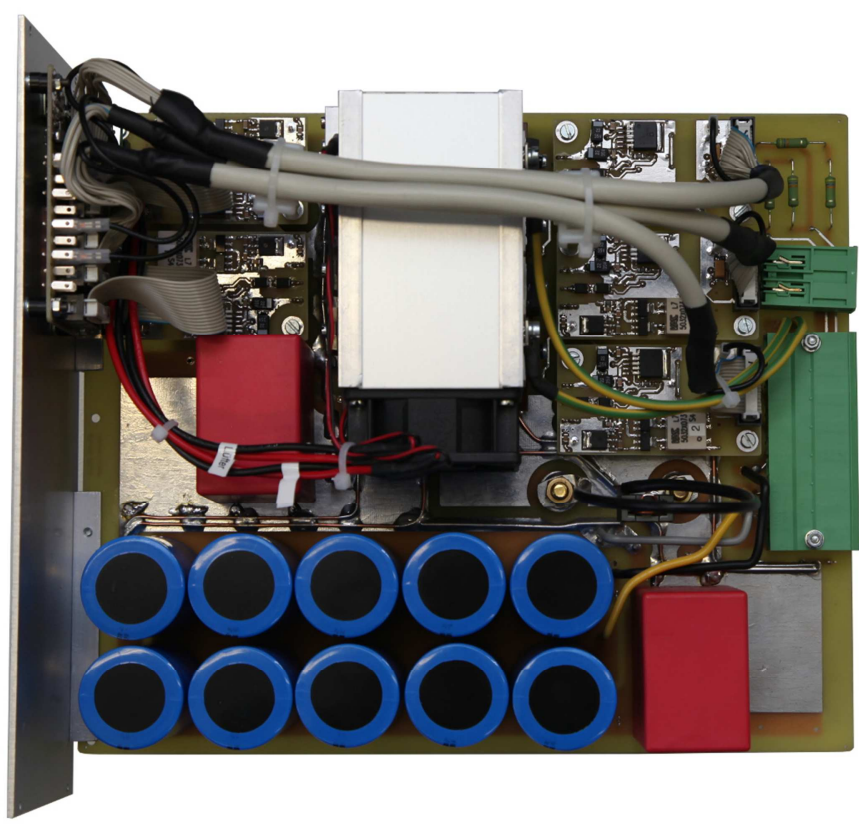

Fig. 5. The PV inverter prototype

TABle I. TeChNical Data of the Prototype

\begin{tabular}{|l|l|l|}
\hline \multicolumn{1}{|c|}{ Description } & \multicolumn{1}{c|}{ Symbol } & \multicolumn{1}{c|}{ Value } \\
\hline AC voltage & $U_{\mathrm{A}}$ & $230 \mathrm{~V}$ \\
\hline Output frequency & $f_{\mathrm{A}}$ & $50 \mathrm{~Hz}$ \\
\hline Switching frequency & $f_{\mathrm{sw}}$ & $12 \mathrm{kHz}$ \\
\hline Rated power & $S$ & $3,7 \mathrm{kVA}$ \\
\hline
\end{tabular}

TABLE II. COMPONENT VALUES AND NAMES

\begin{tabular}{|l|l|}
\hline \multicolumn{1}{|c|}{ Part } & \multicolumn{1}{c|}{ Value / Part Name } \\
\hline C1 & $1750 \mu \mathrm{F}$ \\
\hline C2 & $50 \mu \mathrm{F}$ \\
\hline L1 & Coilcraft SER2011-501ML $(500 \mathrm{nH})+$ 170nH Air Coil \\
\hline L2 & $5 \mathrm{mH}$ \\
\hline D7 & DSEI60-02A \\
\hline T1 & 2x IRG7PH42UDPbF in parallel \\
\hline T2, T4, T5 & IRG7PH42UDPbF \\
\hline T3 & IRG7PH42UPbF + DSEI120-12A in parallel \\
\hline
\end{tabular}

L1 is a Coilcraft SER2011-501ML surface-mounted-device (SMD) inductor with an inductance of $500 \mathrm{nH}$. The saturation current, at which the inductance drops $10 \%$, is specified with 100A [15]. A loop wire in series with L1 is used to connect an external current probe for measurement purposes. This loop adds $170 \mathrm{nH}$ to the inductance of the SMD coil (Fig. 6). L1 is located on the board shown in Fig. 5, whereas L2 and the current sensor for the $\mathrm{AC}$ current $i_{\mathrm{A}}$ are placed externally.

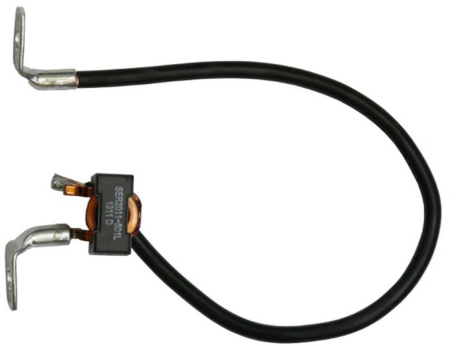

Fig. 6. The inductor L1 with measurement loop

The system is controlled by a TMS320VC33 Digital Signal Processor from Texas Instruments. The DC voltage $U_{\mathrm{D}}$, the capacitor voltage $u_{\mathrm{C} 2}$, the line voltage $u_{\mathrm{A}}$ and the line current $i_{\mathrm{A}}$ are measured by a THS1206 A/D-converter from Texas Instruments with a resolution of 12 bits. An EP1C6 FPGA from Altera is generating the signals for the gate-drivers of T1T5 with a state machine according to Fig. 4. Instead of an FPGA, an ordinary PWM control unit of a microcontroller could be used as well to generate the gate signals for T1-T5 if a few logic circuits are added between PWM control unit and gate drivers.

\section{EXPERIMENTAL RESULTS}

The following measurements have been performed at the $50 \mathrm{~Hz}$ grid with a line voltage of $U_{\mathrm{A}, \mathrm{RMS}}=230 \mathrm{~V}$. A DC laboratory power supply with an external series resistance of $1,8 \Omega$ for decoupling purposes is feeding the inverter. The DC voltage at the input of the circuit is set to $U_{\mathrm{D}}=500 \mathrm{~V}$ and the line current is set to $i_{\mathrm{A}, \mathrm{RMS}}=16,3 \mathrm{~A}$.

Fig. 7 shows the line voltage $u_{\mathrm{A}}$, the three level output voltage $u_{\mathrm{B}}$, the line current $i_{\mathrm{A}}$ and the charging current $i_{\mathrm{L} 1}$ at $\cos \varphi=1$.

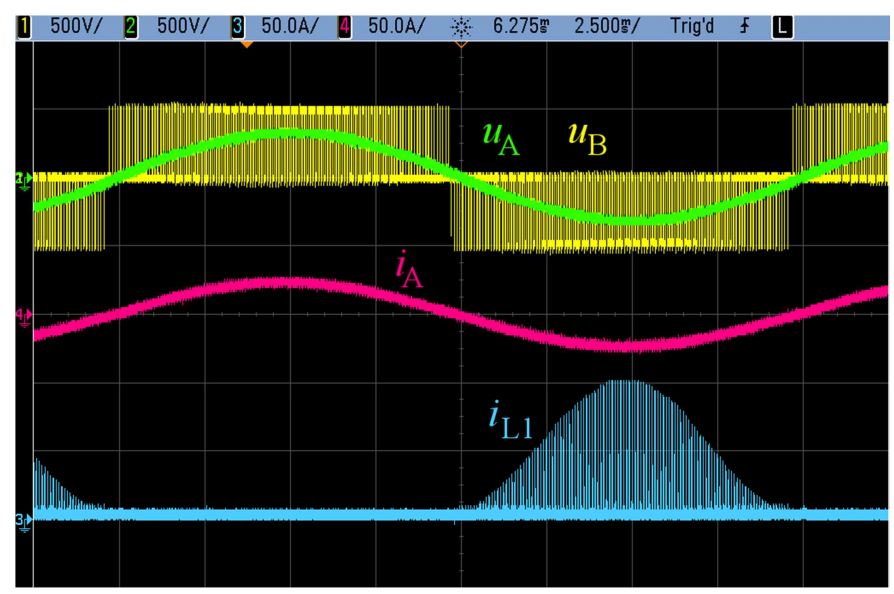

Fig. 7. Line voltage $u_{\mathrm{A}}$, output voltage $u_{\mathrm{B}}$, line current $i_{\mathrm{A}}$ and charging current $i_{\mathrm{L} 1}$ at $\cos \varphi=1$

The ability of delivering capacitive and inductive reactive power at the AC-side has been successfully tested with $\cos \varphi=0,9$. Fig. 8 shows measurement results with leading current and Fig. 9 with lagging current. 


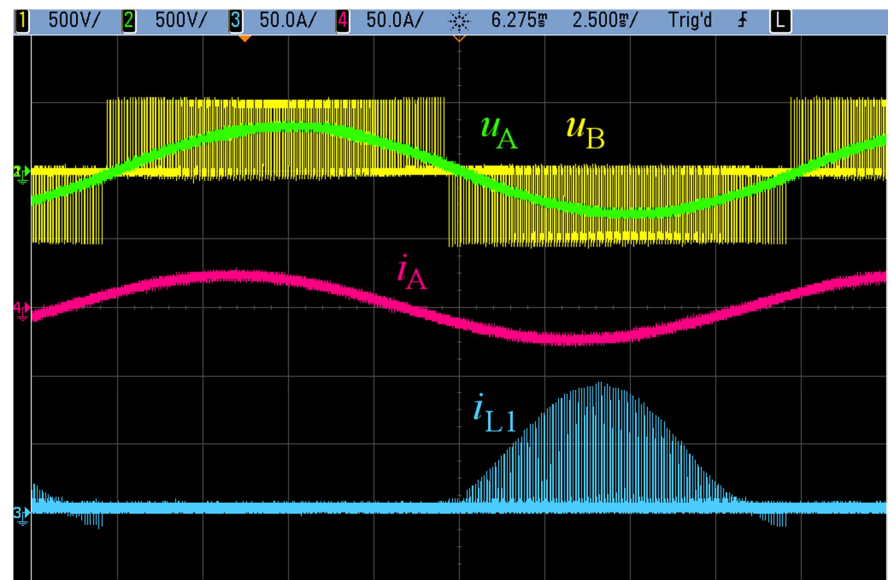

Fig. 8. Line voltage $u_{\mathrm{A}}$, output voltage $u_{\mathrm{B}}$, line current $i_{\mathrm{A}}$ and charging current $i_{\mathrm{L} 1}$ at $\cos \varphi=0,9$; leading current

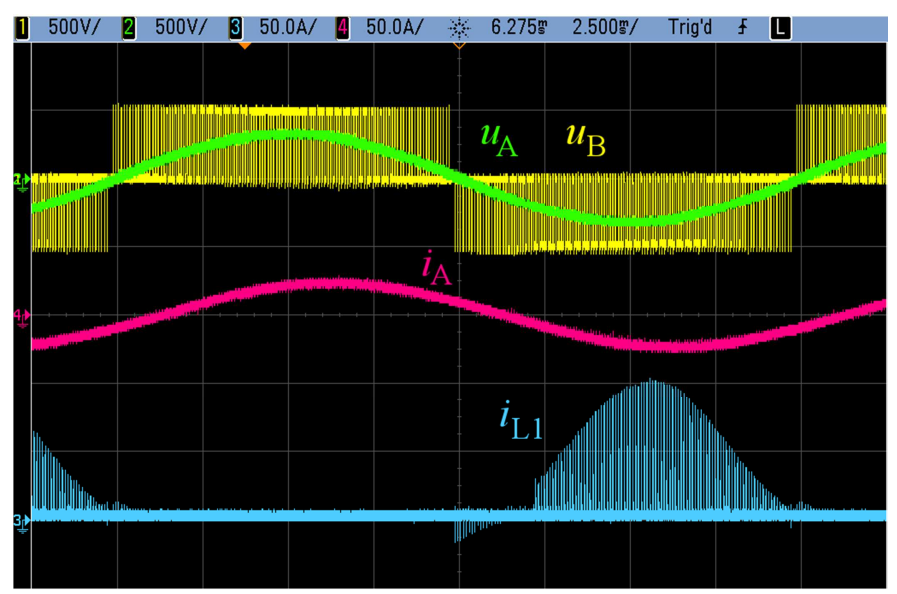

Fig. 9. Line voltage $u_{\mathrm{A}}$, output voltage $u_{\mathrm{B}}$, line current $i_{\mathrm{A}}$ and charging current $i_{\mathrm{L} 1}$ at $\cos \varphi=0,9$; lagging current

The charging current $i_{\mathrm{L} 1}$ is plotted more detailed in Fig. 10. At $U_{\mathrm{D}}=500 \mathrm{~V}, T_{3 \mathrm{~b}}$ is larger than $T_{\text {charge,ZCS, so the charging }}$ process is terminated by $\mathrm{D} 7$ at a current of zero.

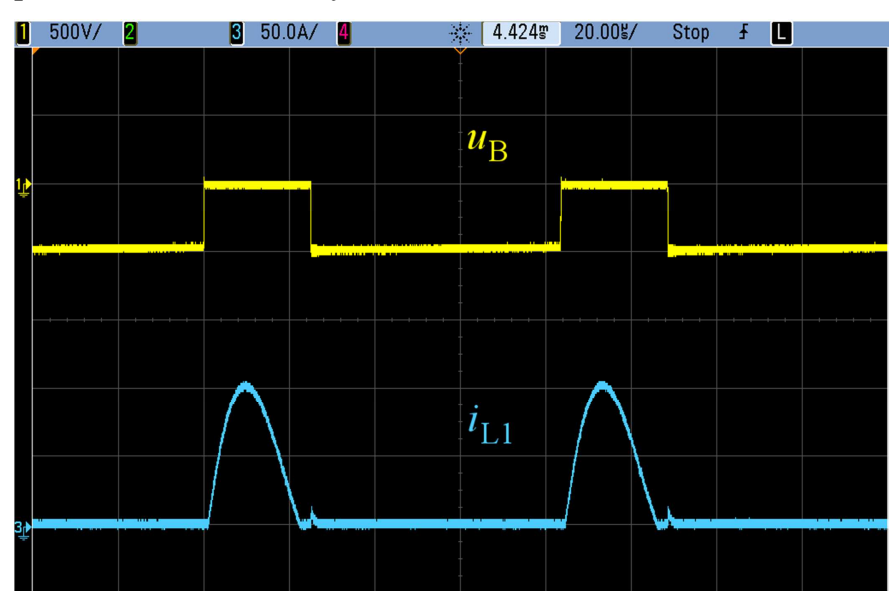

Fig. 10. Output voltage $u_{\mathrm{B}}$ and charging current $i_{\mathrm{L} 1}$ at $U_{\mathrm{D}}=500 \mathrm{~V}$ (two switching cycles)

Fig. 11 shows the charging current at $U_{\mathrm{D}}=450 \mathrm{~V}$, $U_{\mathrm{A}, \mathrm{RMS}}=230 \mathrm{~V}, i_{\mathrm{A}, \mathrm{RMS}}=16,3 \mathrm{~A}$ and $\cos \varphi=1$. At this operating point $T_{3 \mathrm{~b}}$ is smaller than $T_{\text {charge,ZCS. Here, the charging process }}$ is terminated by opening $\mathrm{T} 1$ at a current greater than zero.

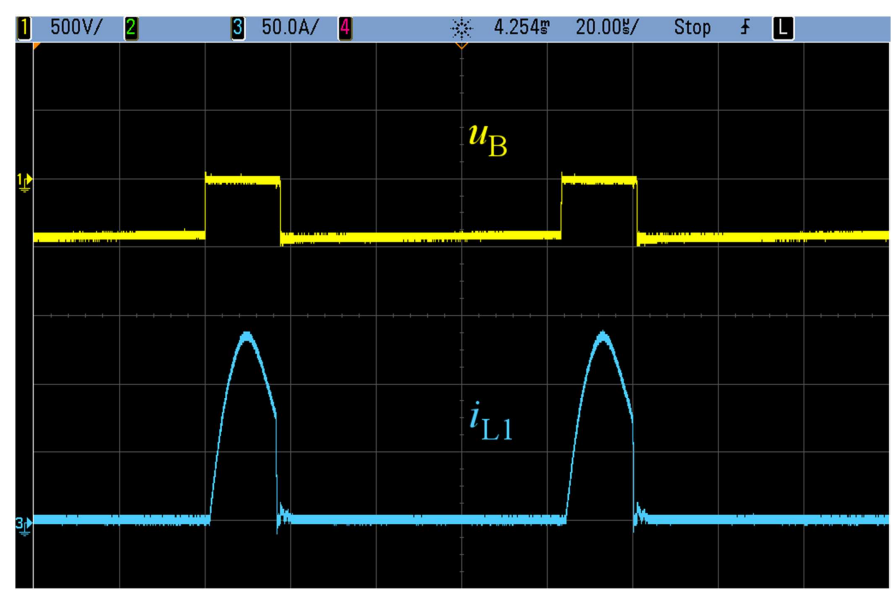

Fig. 11. Output voltage $u_{\mathrm{B}}$ and charging current $i_{\mathrm{L} 1}$ at $U_{\mathrm{D}}=450 \mathrm{~V}$ (two switching cycles)

Efficiency measurements of the circuit were performed with a LMG500 precision power analyzer by ZES Zimmer and the measurement setup shown in Fig. 12, configuration a). The inverter's control system was supplied by an external power supply, so these losses are not taken into account. Fig. 13 shows the measured efficiency $\eta=P_{\mathrm{A}} / P_{\mathrm{D}}$ at different input voltages $U_{\mathrm{D}}$. Below $U_{\mathrm{D}}=450 \mathrm{~V}$, the maximum output power had to be reduced to keep $i_{\mathrm{L} 1}$ in a tolerable range.

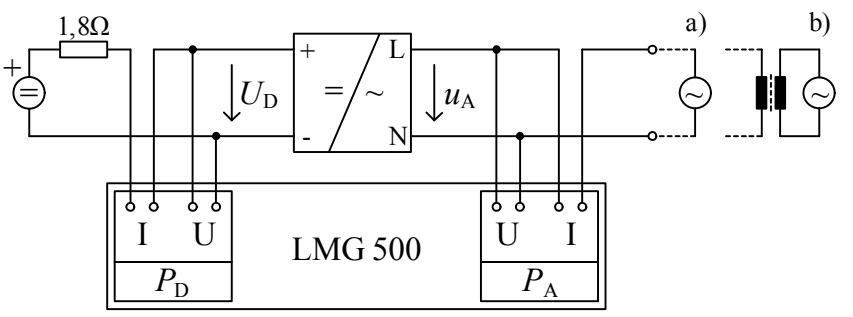

Fig. 12. Setup for efficiency measurement; a) without isolating transformer; b) with isolating transformer

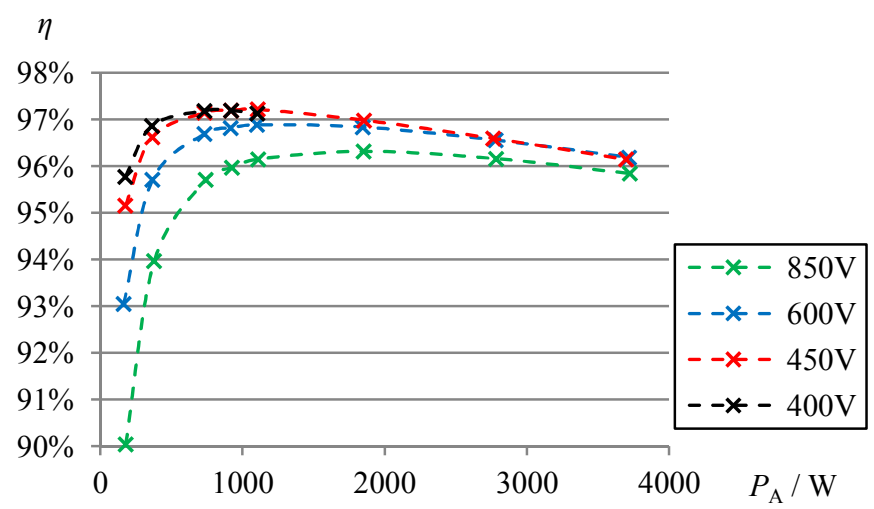

Fig. 13. Efficiency at different values of $U_{\mathrm{D}}$; dashed lines are interpolated

Comparative measurements with an H-Bridge were performed as well to separate the losses in the resonant charging circuit (T1, D7, L1 and T3) from the losses in the AC- 
sided bridge (T2-T5 and L2). For this purpose, the inverter circuit was modified, see Fig. 14, while the semiconductors T2T5, the gate-units and the three level PWM scheme were left unchanged.

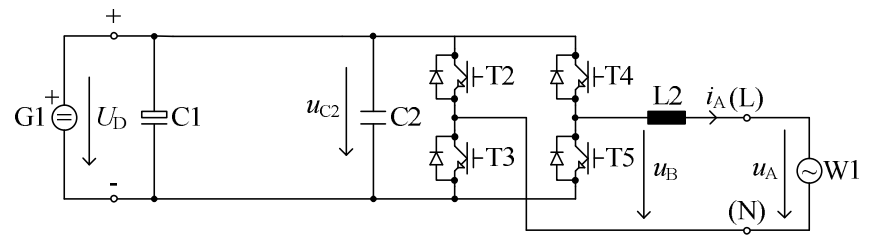

Fig. 14. H-Bridge circuit for loss comparison

The relative additional losses $p_{\mathrm{CC}}$, caused by the resonant charging circuit are calculated with:

$$
p_{\mathrm{CC}}=\frac{P_{\mathrm{D}, \mathrm{TI}}-P_{\mathrm{D}, \mathrm{HB}}}{P_{\mathrm{D}, \mathrm{HB}}}
$$

$P_{\mathrm{D}, \mathrm{TI}}$ is the power at the DC-side of the transformerless inverter circuit (Fig. 1) and $P_{\mathrm{D}, \mathrm{HB}}$ is the power at the DC-side of the H-Bridge at the same operating point. The chosen three level modulation scheme causes capacitive leakage currents with switching frequency at the terminals of the H-Bridge. Therefore an isolating transformer was added, see Fig. 12 b). The transformer was used for the measurement of $P_{\mathrm{D}, \mathrm{HB}}$ as well as for the measurement of $P_{\mathrm{D}, \mathrm{TI}}$.

Measurement results are shown in Fig. 15. Compared to the total inverter losses, the additional losses of the resonant charging circuit are relatively low and decrease with increasing DC voltage $U_{\mathrm{D}}$. The main part of the losses is caused by the AC bridge circuit, consisting of T2-T5 and L2.

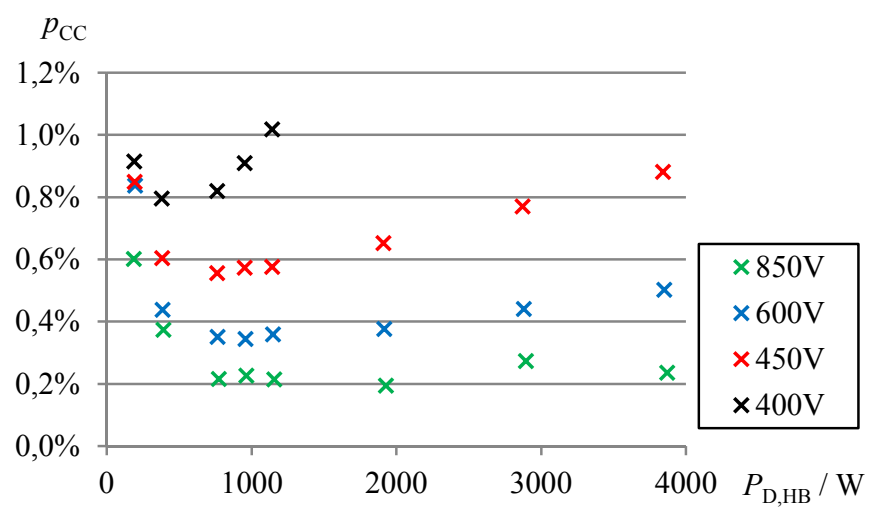

Fig. 15. Relative additional losses of the resonant charging circuit at different values of $U_{\mathrm{D}}$

\section{CONCLUSION}

A new transformerless photovoltaic inverter circuit for thinfilm or back-side contacted solar modules is described in detail. It requires only five transistors and is capable of providing capacitive or inductive reactive power at the AC-side. No capacitive leakage currents occur at the modules, because one pole of the solar module string is connected to the neutral conductor. The three level topology leads to low switching losses and a small AC-sided inductor. All semiconductors do not require significantly higher blocking voltages than the voltage of the solar module string. The energy for one of both half-waves is transferred to the AC-side with a flying capacitor. Its capacitance can be chosen very small, so the usage of a film capacitor with a long lifespan is possible. A prototype has been built up and experimental results show the performance of the inverter.

Compared to a state of the art H-Bridge with three level PWM-scheme, few additional losses occur. If an H-Bridge is used with thin-film or back-side contacted solar modules, an additional isolating element is necessary, e.g. a line transformer or a high-frequency transformer at the DC side. These isolating elements also cause losses. Compared to transformer based solutions, the additional losses of the described circuit with flying capacitor are relatively low.

It has to be considered that the prototype has not been optimized for low losses yet. Therefore it is expectable that the efficiency could be further increased by the use of optimized components e.g. silicon carbide semiconductors.

\section{REFERENCES}

[1] C. Osterwald, T. McMahon, and J. del Cueto, "Electrochemical corrosion of $\mathrm{SnO} 2: \mathrm{F}$ transparent conducting layers in thin-film photovoltaic modules," Solar Energy Materials \& Solar Cells, vol. 79, 2003.

[2] R. Swanson, M. Cudzinovic, D. DeCeuster, V. Desai, J. Jürgens, N. Kaminar, et al., "The surface polarization effect in high-efficiency silicon solar cells," 15th PVSEC, 2005.

[3] VDE, "VDE-AR N 4105 Anwendungsregel: 2011-08 Erzeugungsanlagen am Niederspannungsnetz," ed, 2011.

[4] H. Schmidt, C. Siedle, and J. Ketterer, "DC/AC converter to convert direct electric voltage into alternating voltage or into alternating current," US7046534B2, 2004.

[5] M. Victor, F. Greizer, S. Bremicker, and U. Hübler, "Method of converting a direct current voltage from a source of direct current voltage, more specificially from a photovoltaic couse of direct current voltage into a alternating current voltage," US20050286281A1, 2005.

[6] R. Gonzalez, "Single-phase inverter circuit for conditioning and converting DC electrical energy into AC electrical energy," EP2053730A1, 2006.

[7] W. Yu, J.-S. Lai, H. Qian, and C. Hutchens, "High-Efficiency MOSFET Inverter with H6-Type Configuration for Photovoltaic Nonisolated ACModule Applications," Power Electronics, IEEE Transactions on, vol. 26, pp. 1253-1260, 2011.

[8] W. Cui, B. Yang, Y. Zhao, W. Li, and X. He, "A novel single-phase transformerless grid-connected inverter," in IECON 2011 - 37th Annual Conference on IEEE Industrial Electronics Society, 2011, pp. 11261130 .

[9] S. B. Kjaer, J. K. Pedersen, and F. Blaabjerg, "A review of single-phase grid-connected inverters for photovoltaic modules," Industry Applications, IEEE Transactions on, vol. 41, pp. 1292-1306, 2005.

[10] D. Karschny, "Wechselrichter," DE19642522C1, 1996.

[11] H. Schmidt and B. Burger, "Wechselrichteranordnung zum Einspeisen von photovoltaisch gewonnener Energie in ein öffentliches Netz," DE102008050765A1, 2008.

[12] P. Zacharias and B. Sahan, "Apparatus for feeding electrical energy into a power grid and dc voltage converter for such an apparatus," US20090201706A1, 2009.

[13] B. Burger and H. Schmidt, "Isolating circuit for inverters," US20110255316A1, 2009.

[14] Y. Gu, W. Li, B. Yang, J. Wu, Y. Deng, and X. He, "A transformerless grid connected photovoltaic inverter with switched capacitors," in Applied Power Electronics Conference and Exposition (APEC), 2011 Twenty-Sixth Annual IEEE, 2011, pp. 1940-1944.

[15] Datasheet - Coilcraft Shielded Power Inductor SER2000. 